\title{
The Professional Performance of
} the General Practitioner in Social Work and the Improvement of Health Care Services

\author{
Ahmed Zaki Mohamed (PhD) \\ Assistant Professor at the Department of Social Work Fields \\ Higher institute of Social Work in Cairo
}

Mohamed Abdel-Hamid Morsy Mohamed (PhD)

Assistant Professor Department of Social Work Fields Higher Institute for Social work in Cairo 
The Egyptian Journal of Social Work (EJSW) https://ejsw.journals.ekb.eg/e ISSN: 2356-9204 Vol 11, Issue.1, January2021 
The Egyptian Journal of Social Work (EJSW) https://ejsw.journals.ekb.eg/e

ISSN: 2356-9204

Vol 11, Issue.1, January2021

\section{Abstract:}

This study outlines the relationship between the professional performance of the general practitioner and the improvement of health care services. We selected a purposeful sample from (45) social workers. The findings illustrated that there is a statistically significant relationship between the professional performance of the general practitioner and the improvement of health care services. At the level of importance $(0.01)$, there is a close relationship between the professional performance of the general practitioner and the improvement of economic services. Similarly, this correlation has been observed between the professional performance and the improvement of health care services.

\section{Key words}

Professional Performance; Health Care Services.

\section{Introduction:}

The health sector is the most momentous service that is involved in improving the economic and human development of a country. Indeed, the human potential is a substantial resource that requires a special care to be able to perform its roles in society efficiently and constantly. Hence, the success of any development effort depends on the physical, mental, psychological and social integrity of the person. (Omran, 1999: 113). Despite the concern in the human potentials in both developed and developing countries, several health and social problems usually hinder their development (Hasa, 1997:10). As a result, the improvement of the healthcare system is one of the demanding areas for a society. Additionally, it is a fundamental right for all people to receive quality healthcare services, whether are preventive or curative. These desired goals will benefit both the welfare of the people and society (Abdel-Moaty et al., 2012:377).

Hasan (2006:5) noted that physical health is a key aspect to mental health, so it is very vital to develop health care services to obtain effective social changes. According to Michele, el. (2013), there are several factors that are related to the quality services, namely the inability of patients to adapt to their diseases, treatment refusal and a lack of cooperation with the social worker. Lindsay, et al, (2009) also asserts the practice of social workers in the medical field within the framework of general practice and the provision of services to individuals suffering from social exclusion. Additionally, the study emphasizes the vital role of social workers in helping patients to obtain medical, health and social care services. The study is concluded 
The Egyptian Journal of Social Work (EJSW) https://ejsw.journals.ekb.eg/e

by giving some suggestions to pay attention to scientific planning to provide services that could be explained in the following points:

\section{A. Social services:}

Social medical services are among the services that can be provided to patients by social worker in hospitals. These services include the following:

1. Conducting social research by making a special report for the patient and his family to alleviate negative emotions.

2. Organizing social programs to encourage parents to visit their patients in hospitals.

3. Finding a place to host the patient's family if they live in an area far from the hospital.

4. Providing the appropriate blood type for each patient, as it is one of the common problems (Abu Al-Maati, 2012:47).

\section{B- Economic services}

The issue of providing economic medical services to patients is of great importance, so the social worker in hospitals should consider the following:

1. The compensatory amount of the injured must be reviewed and paid as it is identified by the court.

2. To provide modern and advanced devices that suit the age and nature of each patient in hospitals.

3. To compel doctors and hospitals to the extent that the patient needs to obtain insurance for medical errors.

4. To transfer the patient to other institutions for further assistance.

\section{C- Medical and health care services:}

These services are based on intensifying the doctors' efforts to achieve hospital reform and assist the injured by the treated medical team. The social worker in hospitals have to work in partnership with the medical team though the following contributions:

1. They have to periodically perform tests and monitor patients until they are hospitalized.

2. They have to make sure that the medication is compatible with the patient's condition.

3. They have to provide patients with home health care to enhance their sense of safety.

However, if it is permitted to ensure the success of medical treatment, it is necessary to develop the competences of the social specialist. This is because he is one of the professionals who is involved in the areas of community development. Therefore, he can 
The Egyptian Journal of Social Work (EJSW) https://ejsw.journals.ekb.eg/e ISSN: 2356-9204

Vol 11, Issue.1, January2021

play a vital role in terms of the need to social work (Mahmoud, 2013). He has also to identifty the obstacles that affect the professional performance of social workers in the medical field. Mahmoud (2013) recommended an effective program for developing professional creativity of social workers in the medical field.

Lindsay, et al. (2009) also focused on the practice of social workers for their work in the medical field within the framework of general practice and the provision of services to individuals suffering from social exclusion. This study emphasized the vital role of social workers in helping patients to obtain medical, health and social care services. It suggested the need to pay attention to scientific planning to provide services.

Furthermore, Slak (2007) showed the significance of assessing the needs for knowledge and skills to raise the proficiency of social workers in the medical field in a way that develops their professional performance. This profession still depends on the social specialist's skills where his personality plays a fundamental role in performing his professional work. Indeed, the social service is still characterized by an artistic skill that depends on the social worker's performance and his own personality. Additionally, it relies on the ongoing need to gain more knowledge and experience. This expertise can refine the social worker's personality and make him more able to fulfill his responsibilities. Similarly, Hashem (2005) emphasized the importance of training in developing the professional performance of social workers in terms of efficiency, skills and knowledge.

\section{Theoretical framework}

The general practice is theoretically based on a basic idea that the human being continuously tries to satisfy his needs, develops his experiences and skills, and strikes a balance in interacting with society in various forms. This concept depends on a simple fact that the human being is an essential part of the environment in which he lives, as he is in constant interaction, influencing and being affected by it. Since man does not live alone in this universe, he communicates with individuals and groups within his society through a set of human relations that are characterized by complexity and overlapping. Hence, the inability of a person to satisfy his needs in an integrated manner is a result of: pressures and conflicts that may occur because of a lack of interaction in the environment; complexity of relations and interests; imbalance in the levels of power and influence. Therefore, many problems may appear and affect the capabilities of individuals, families, groups, institutions, and societies (El-Nouhy, 2002:11). 
The Egyptian Journal of Social Work (EJSW) https://ejsw.journals.ekb.eg/e

ISSN: 2356-9204

Vol 11, Issue.1, January2021

The underlying principle of general practice relies on the concept of a selective electric perspective in professional intervention. This is based on the opportunity to provide a social worker with freedom to choose what he deems appropriate for the client at different levels: individual, group, small community or institution. Indeed, the professional methods are based on a variety of scientific approaches and theories. These models and theories depend on each other in many aspects, namely the objectives of the intervention, the quality of methods, the means of estimation, and the duration of the intervention. Thus, the variations and differences may be extremely beneficial to the social worker when dealing with the various problems of clients (Derezates, 2005:75).

However, the major goals of general practice in social work seek to achieve the following:

1. Helping people to increase their efficiency and abilities to solve problems or adapt to them by helping them choose the best alternatives to face these problems.

2. Assisting people to obtain the available resources and directing them to take advantage of the institutions that provide the services they need.

3. Increasing people's benefits from institutions and increasing their response to them.

4. Facilitating interactions between different entities in the social environment.

The major interest of social service has increased by using the theory of ecological patterns that considers different interactions between people and their social environments. This is to investigate the internal and external factors affecting their behavior. This theory focuses not only on the person, tackling his problems on environmental patterns to address his human needs but also on the relationship between all of them together and at the same time (Abdel Majid, 2005: 3480).

The social worker is a general practitioner of environmental concepts in his intervention with the professional work team. This could be obtained by bypassing the traditional methods that depend on the medical or pathological perspective and consider the client as a negative person who depends on others, especially when the social institution is seeking for help without taking into account the environmental factors. These factors may be mainly responsible for his problems and obstacles. This theory is mainly based on an environmental scale in which people live. In fact, there is no room to 
think about individual human behavior independently. This due to the environmental interaction and the mutual influences between the pattern and the environment (El-Nouhy, 2002. P. 87).

The interaction between the person and his environment is not bilateral. As there is no survival outside the environment, in which the individual is integrated into it, so the concentration of the general practitioner and social worker must be concentrated on the points of convergence between the client's pattern and the environment, i.e. to the process of interaction and communication with them, parents and their environment together form a dynamic interactive pattern (Zymula, et al., 1999, p. 224). In addition, boundaries play a vital role in determining the openness or closure of the pattern, the patterns that allow their boundaries to exchange inputs and outputs with other entities in the environment are open patterns, and patterns whose boundaries do not allow them to do so are closed (Gary and Bradford, 2016:175).

\section{Study Objectives:}

The study seeks to achieve the following objectives:

1. Determine the nature of the relationship between the professional performance of the general practitioner in social work and the improvement of health care services for patients.

2. Determine the nature of the relationship between the professional performance of the general practitioner in social service and the improvement of economic services.

3. Determine the nature of the relationship between the professional performance of the general practitioner in social work and the improvement of social services.

\section{Study concepts:}

\section{Professional performance}

Profession is a type of activity that has value in accordance with the formal market standards. The individual is keen to practice it continuously to ensure that he gets a regular rate of income and that the professional activity of those who practice it achieve an appropriate social status (Allam, 2009:294).

It is also known as: the process that takes place between clients and a social worker (Al Badawi \& Khalifa, 2011, p. 15). It is defined as a "perspective on the nature of the practice of social work in which attention is focused on solving social problems and satisfying human needs, and achieving social justice and the general practitioner chooses from theories and models to suit the patterns with which he deals."(Garven,C,2017), Abu Al-Maati (2014) defines general practice 
as the trend of professional practice in which the social worker focuses on using environmental patterns and technical methods to solve the problem without preferring to focus on applying a method of social service to help beneficiaries of social services. This is to satisfy their needs, address their problems and take into account all the methods of dealing, including individual, family, small group or community. Such a pattern is based on the foundations of knowledge, skill and value reflecting the individual nature of the practice of social service in dealing with other disciplines, to achieve in accordance with the field of practice (Abu Al-Maati, 2014, p.30).

The employee's performance of his work is an interaction between his own characteristics and job requirements that are directly affected by the incentives and training system. In light of the leadership and care systems that flow from the company's system, we find the heads and managers at any administrative level and in any organization or company who are deeply interested in the performance of their employees. This is because the professional performance is not only a reflection of the capabilities and motivation of each employee, but also a reflection of the performance of the whole company (Ammar, 2002, p. 34).

Some authors also believe that the concept related to performance is the concept of productivity, which refers to what includes both effectiveness and efficiency, where 'effectiveness' refers to the goals achieved or the achievement of the goals set by the organization regardless of the costs resulting from these goals. As for 'efficiency', it refers to the ratio of consumed inputs to the outputs obtained, where the more the outputs are more than the inputs, the higher the efficiency will be obtained (Abbas and Ali, 1999, p. 242).

\section{Foundations of the professional performance of the general practitioner:}

The foundations of the general practitioner's professional performance in social worker include the following:

1. Clarity of the objective and trends of the organization for the general practitioner.

2. Both the social worker and the team understand the tasks assigned to them by the foundation.

3. Support and encourage the performance of the social worker and motivate him to achieve his confidence.

4. Conduct the evaluation process for the social worker to see what has been achieved (Harvard, 2001:18). 
The Egyptian Journal of Social Work (EJSW) https://ejsw.journals.ekb.eg/e

ISSN: $2356-9204$

Vol 11, Issue.1, January2021

\section{Factors affecting the professional performance of the general practitioner:}

1. The personal and social factors of the social worker such as age, gender, qualification, etc.

2. Professional factors such as professional preparation, ongoing training, etc.

3. Factors associated with the field of practice before work and during the relationship with colleagues and presidents.

4. Community factors such as social service image in the community as well as the extent to which other institutions cooperate with the social worker (Douglas, 2004: 94).

\section{The professional performance of the general practitioner:}

The professional performance of the general practitioner in the social work is determined by the following:

1. Cognitive basis: The professional knowledge contributing to the development of the performance of the social worker must, therefore, rely on the knowledge given effectiveness of his work and help him to understand and study human behavior as well as its motives and factors affecting it (Wilson, 2006, p. 182).

2. Skills foundation: The general practitioner in the social service with different formats has to improve the level of medical services and define skills. He should also be able to employ theories, knowledge, experiences and professional principles to develop his performance in the fields of practice to achieve the process of assistance to all the entities he deals with in multiple situations with the economy of time and effort (Donald,2003: 16). Accordingly, the skills' acquisition of social workers could be emphasized by describing professional skills as a requirement for improving professional performance because professional skills are a true product of what has been acquired through the knowledge, principles and professional values.

3. Value basis: Values are a set of beliefs and standards acquired by a specialist as a general practitioner as a guide to achieving the objectives of professional practice towards clients, colleagues, institutions, the social service profession, and society as a whole (Al-Ghazzawi, 2004, p. 34). It is all that ensures functionality, and performance indicates how the activity or function is done (Cambridge Dictionary of American English:2000: 630). It is also defined as starting and continuing to do something until it is finished or taking action according to certain requirements, or achievement and implementation while not confusing the quality 
The Egyptian Journal of Social Work (EJSW) https://ejsw.journals.ekb.eg/e

ISSN: 2356-9204

Vol 11, Issue.1, January2021

of performance on the one hand with behaviors or work activities, duties and responsibilities on the other (Pierce et al, 2002, p. 260).

4. Professional Performance Procedure can be introduced as follow:

a) The general practitioner in the social service performs his professional duties and responsibilities to apply professional knowledge, skills and values with different formats to improve the level of health care services.

b) The general practitioner uses tools, techniques, strategies and professional roles with different formats to improve the level of health care services.

c) This practice is done in a deliberate manner in the light of the factors affecting the surrounding environment.

5. The level of performance: It is a way to improve and raise the performance of the organization through the individual working in it, and it is a process of continuous communication and cooperation between employees and officials in the organization.

\section{B - The concept of health care services:}

Health care includes a specific set of basic services provided by the state to take care of the health of citizens and provide treatment for health problems to prevent diseases and improve health behaviors. Those who are involved in providing these services include public and private institutions, namely hospitals, pharmacies and clinics, and human resources, including doctors, nurses, and anyone who works in the medical field or medical research (Abu Al-Maati, 2011, p.199).

Access to health care varies across countries, communities and individuals, and it is greatly influenced by socio-economic conditions as well as existing health policies. Countries and jurisdiction have different policies and plans regarding the goals of personal and population health care in their commutations created to meet the health needs of a population. According to World Health Organization (WHO), a well- functioning health care system requires strong funding, a well-trained and adequately paid workforce, reliable information on which decisions and policies are based, and highquality medicines and devices (Health topics, Health systems, 2019:143).

The objective of the health care system is to respond to the needs and expectations of the population, improve their health status, defend everything that threatens it, and also protect the population form the financial problems they face when they are exposed to health deteriorates. This could be achieved by providing equitable access to 
adequate healthcare by empowering them to participate in decision that affect their health system and their health (Gregory, 2019, p.24).

The social work has emerged in developed societies since the early $20^{\text {th }}$ century as an inevitable response to the needs of the human being of this age. The social work was a result of long experience and continuous efforts to encounter human problems resulting from the social changes that accompanied the industrial revolution and the complexity of life. Due to these problems and increasing pressures, the existing social systems were unable to cope at a time when these systems have lost a significant part of their traditional effectiveness (Bashir et al: 1987, pp.12-13).

Operational definition of medical care service

It is an area of the social service profession practiced by social workers in medical institutions. These services contribute to improve the level of health care provided to the clients. It consists of four dimensions that are; Economic Services, Health services, Psychiatric services, and Social services.

\section{Methodology:}

This study belongs to the pattern of descriptive and analytical studies that determine the relationship between two variables, professional performance of the general practitioner in social work and improving of health care services. This study uses the method of the social survey sample.

\section{Study hypothesis:}

1. There is a positive statistically significant relationship between the professional performance of the general practitioner in social work and the improvement of health care services for patients.

2. There is a positive statistical significance between the professional performance of the general practitioner in social work and the improvement of economic services.

3. There is a positive statistically significant direct relationship between the professional performance of the general practitioner in social work and the improvement of social services.

\section{Sample}

The study sample was chosen using the comprehensive social survey method for all social workers at Atfih and Hawamdia and ElAyyat Central Hospital. The number of annual beneficiaries of health care services is approximately (3850) families. The content of $60 \%$ was analyzed from the files of beneficiaries in hospitals in the group of services that provide family members, The groups of beneficiaries vary from woman and men, young children and the 
The Egyptian Journal of Social Work (EJSW) https://ejsw.journals.ekb.eg/e ISSN: 2356-9204

Vol 11, Issue.1, January2021

elderly who are eligible from Giza Governorate, and the total size of the study sample was determined by (45) social workers. The dates of the study were from July 1, 2019 to August 30, 2019.

\section{Methods of statistical analysis:}

The data was processed through a computer using (SPSS.V.17.0, statistical packages of social sciences). The following statistical methods have been applied: iterations and percentage, the arithmetic average, standard deviation, stability coefficient (Alpha Kronbach) and Pearson Link Coefficient.

\section{Study tools}

Data collection tools were:

\section{(1) Measure the professional performance of the general practitioner in the social work:}

(a) Setting the scale: The tool is designed according to the following steps:

- The researcher designed the professional performance of the general practitioner in the social work, by reference to the theoretical heritage, the conceptual framework directed to the study, and refer to the related studies and measures the professional performance of the general practitioner in the social work to determine the terms that are related to each variable of the study.

- The measure of the professional performance of the general practitioner shall be from the axes, including:

The centerpiece of the professional performance of the customers and the terms of the axis were $(1,4,7,10,13,16,19,22,25)$ where the number of phrases for the axis was nine.

The centerpiece of professional performance for colleagues was the axis phrases $(2,5,8,11,14,17,20,23,26)$ where the number of phrases for the axis was 9 .

The centerpiece of professional performance in the range of professional positions was the axis phrases $(3,6,9,12,15,17,20,24$, 27) where the number of phrases for the axis was 9.

\section{The method of correcting the scale:}

Ok given (3) To some extent given (2) Unfavorable given (1) b) Validity and reliability of the professional performance scale(the arbitrators validated) and (to ensure the professional performance measure, the researcher used the coefficient of stability of Alpha Cronbach based on the standard error by applying the scale to the exploratory sample of exploratory sample of 10 specialists the value of Alpha Cronbach stability was $(0.882)$. 
The Egyptian Journal of Social Work (EJSW) https://ejsw.journals.ekb.eg/e

ISSN: 2356-9204

Vol 11, Issue.1, January2021

c) Methods of statistical analysis the data were processed by computer using the program (spss.v.19.0), and the following statistical methods were applied: 1) Repetitions and percentages. 2) Alpha Cronbach factor 3) Correlation coefficient t.test.

d) The validity of the measure of the professional performance of the general practitioner in the social work:

1. Content validity:

To confirm the validity of the measure of the professional performance of the general practitioner in the social work, the researcher presented the dimensions of the scale to ten experts in the social work and the results were as follows:

Table (1) the frequencies and percentage of expert opinions on the dimensions of the performance measure of the general practitioner in the social work $(\mathrm{N}=10)$.

\begin{tabular}{|l|l|l|l|}
\hline$M$ & Dimensions frequency & Percent \\
\hline 1 & Professional performance towards customers & 10 & $100 \%$ \\
\hline 2 & Professional performance towards colleagues & 9 & $\mathbf{9 0 \%}$ \\
\hline 3 & $\begin{array}{l}\text { Professional performance towards the } \\
\text { institution }\end{array}$ & $\mathbf{3}$ & $\mathbf{3 0 \%}$ \\
\hline 4 & $\begin{array}{l}\text { Professional performance towards professional } \\
\text { positions }\end{array}$ & $\mathbf{1 0}$ & $\mathbf{1 0 0 \%}$ \\
\hline
\end{tabular}

It is clear from Table (1) that the percentage of expert opinions ranged from (30\%-100\%). The researcher accepted a minimum of $80 \%$ to accept the opinions of the experts, where it was excluded after (professional performance towards the institution) to get $30 \%$ which is less than $80 \%$, so the dimensions of the measure of the professional performance of social workers became (professional performance towards clients, professional performance towards colleagues, professional performance towards professional positions) respectively.

\section{Internal consistency:}

The researcher used the sincerity of internal consistency to calculate the honesty factor in order to verify the sincerity of the measure, where the measure of the professional performance of the general practitioner in the social service was applied to a group of (10) from the research community and outside the basic research sample.

Table (2) the correlation coefficients between the sum of each dimension and the total for the professional performance measure of the general practitioner in the social worker $(\mathrm{N}=10)$.

\begin{tabular}{|l|l|l|}
\hline $\mathrm{M}$ & Dimensions & $\begin{array}{l}\text { The value of } \\
(\mathrm{r}) \text { calculated }\end{array}$ \\
\hline 1 & Professional performance towards customers & $\mathbf{0 . 8 9}$ \\
\hline 2 & Professional performance towards colleagues & $\mathbf{0 . 9 1}$ \\
\hline 3 & $\begin{array}{l}\text { Professional performance towards } \\
\text { professional positions }\end{array}$ & $\mathbf{0 . 8 8}$ \\
\hline
\end{tabular}

$R$-value at $0.05=0.44$ 
It is clear from table (2) that the correlation coefficients between the sum of each dimension and the total score of the scale ranged from (0.88:0.91), which are statistically function correlation coefficients at the level (0.05), indicating the sincerity of the internal consistency of the scale as a whole.

(c) The reliability of the measure of the professional performance of the general practitioner in the social work:

To ensure the reliability of the measure of the professional performance of the general practitioner in the social work, the researcher used the Alpha Cronbach stability factor built on the standard error by applying the scale to the sample of 10 specialists and reapplying in a period of at least 15 days and the results were as follows:

Table (3) Alpha Cronbach for Stability

\begin{tabular}{|l|l|l|}
\hline Number of dimensions & Alpha Cronbach & Alpha Cronbach Standard \\
\hline $\mathbf{3}$ & $\mathbf{0 . 8 3 1}$ & $\mathbf{0 . 8 7 2}$ \\
\hline
\end{tabular}

Table (4) shows the results of a stability laboratory using Alpha Cronbach in the test method and returning it to the professional performance measure of the general practitioner in the social work.

\begin{tabular}{|l|l|l|}
\hline Dimensions & $\begin{array}{l}\text { Number of } \\
\text { Paragraphs } \\
\text { Dimension }\end{array}$ & $\begin{array}{l}\text { Alpha } \\
\text { Cronbach } \\
\text { Coefficient }\end{array}$ \\
\hline Professional Performance towards Customers & 9 & 0.708 \\
\hline Professional Performance for Colleagues & 9 & 0.789 \\
\hline $\begin{array}{l}\text { Professional performance toward professional } \\
\text { positions }\end{array}$ & 9 & 0.811 \\
\hline Total Scale & 27 & 0.856 \\
\hline
\end{tabular}

It is clear from the results of the tables (3) and (4) that the scale has a high Alpha Kronbach stability factor ranging from (0.708 to 0.856) confirming the stability of the scale and allowing it to be used for the purposes and achievement of the research goal.

(2) Health Care Services level scale

(a) Setting the scale

The tool is designed according to the following steps:

- The researcher designed the scale of the level of medical services, by reference to the theoretical heritage, the conceptual framework directed to the study, and refer to related studies and measures of the level of medical services to determine the terms that are related to each variable of the study.

- The measure of the level of medical services shall be from the axes, including: 
The Egyptian Journal of Social Work (EJSW) https://ejsw.journals.ekb.eg/e

ISSN: $2356-9204$

Vol 11, Issue.1, January2021

-The axis of economic services was represented in the terms of the axis $(1,4,7,10,13,16,19,22)$ where the number of phrases for the axis was 8 .

-The axis of health care services was represented in the terms of the axis $(2,5,8,11,14,17,20,23)$ where the number of phrases for the axis was 8 .

-The axis of social services consisted of $(3,6,9,12,15,17,20$,

24) where the number of phrases for the axis was 8 .

\section{- The method of correcting the scale}

OK given (3) To some extent given (2) Unfavorable given (1)

(b) Believe the scale of the level of medical services:

1. The content validity

To confirm the validity of the scale of the level of medical services, the researcher presented the dimensions of the scale to ten experts in the social service supplement (3) and the results were as follows:

Table (5) shows the repetitions and percentage of expert opinions on the dimensions of the medical service level scale $(\mathrm{N}=10)$.

\begin{tabular}{|l|l|l|l|}
\hline $\mathrm{M}$ & Dimensions & Duplicates & Percentage \\
\hline 1 & Economic Services & 10 & $100 \%$ \\
\hline 2 & Health services & 9 & $90 \%$ \\
\hline 3 & Psychiatric services & 3 & $30 \%$ \\
\hline 4 & Social services & 7 & $70 \%$ \\
\hline
\end{tabular}

It is clear from the table (5) that the percentage of expert opinions ranged from (70\% to $100 \%)$ The researcher accepted a minimum of $80 \%$ to accept the opinions of the experts, and was excluded after psychological services (30\%) Therefore, the dimensions of the scale of the level of medical services are (economic services, health services, social services) respectively.

\section{Internal consistency}

The validity of the scale:

The researcher used internal consistency to calculate the validity in order to verify the correctness of the scale, where the scale of the level of medical services was applied to a group of (10) from the research community and outside the basic research sample.

Table (6) shows the correlation coefficients between the sum of each dimension and the total For Health Care Services level scale $(\mathrm{N}=10)$.

\begin{tabular}{|l|l|l|}
\hline $\mathbf{M}$ & Dimensions & The value of $(\mathbf{r})$ calculated \\
\hline 1 & Economic Services & 0.78 \\
\hline 2 & Health Services & 0.88 \\
\hline 3 & Social Services & 0.84 \\
\hline
\end{tabular}

Table (6) value at $0.05=0.44$ 


\begin{tabular}{|cr|}
\hline The Egyptian Journal of Social Work (EJSW) https://ejsw.journals.ekb.eg/e \\
ISSN: $2356-9204$ & Vol 11, Issue.1, January2021 \\
\hline
\end{tabular}

It is clear from table (19) that the correlation coefficients between the sum of each dimension and the total score of the scale ranged from (0.88:0.91), which are statistically function correlation coefficients at the level (0.05), indicating the sincerity of the internal consistency of the scale as a whole.

\section{(c) The Reliability of the Health Care Services level scale: -}

To ensure the reliability of the standard measure of Health Care Services, the researcher used the Alpha Cronbach reliability factor built on the standard error by applying the scale to the sample of 10 families and reapplying in at least 15 days and the results were as follows:

Table (7) Alpha Cronbach for Reliability.

\begin{tabular}{|l|l|l|}
\hline Number of dimensions & Alpha Cronbach & Alpha Cronbach Standard \\
\hline 3 & 0.781 & 0.848 \\
\hline
\end{tabular}

Table (8) shows the results of a stability laboratory using Alpha Kronbach by testing method and returning it to the Health Care Services level scale $(\mathrm{N}=10)$.

\begin{tabular}{|l|l|l|}
\hline Dimensions & $\begin{array}{l}\text { Number Paragraphs } \\
\text { Dimension }\end{array}$ & $\begin{array}{l}\text { Alpha Cronbach } \\
\text { Coefficient }\end{array}$ \\
\hline Economic Services & 8 & 0.623 \\
\hline Health Services & 8 & 0.762 \\
\hline Social Services & 8 & 0.781 \\
\hline Total Scale & 24 & 0.784 \\
\hline
\end{tabular}

The results of my table (7) (8) to ensure the stability of the Health Care Services level scale show that the scale has a high Alpha Cronbach stability factor of 0.623-0.784 that confirms the stability of the scale and allows it to be used for the purposes of achieving the research objective.

\section{Results}

Table (9) Demographic Variables

\begin{tabular}{|l|l|l|l|}
\hline \multirow{2}{*}{ SR } & Demographic variables & Repetition & Percentage \\
\cline { 2 - 4 } & Gender & $\mathrm{K}$ & $\%$ \\
\hline 1 & Male & 30 & $66.7 \%$ \\
\hline 2 & Female & 15 & $33.3 \%$ \\
\hline & Total & 45 & $100 \%$ \\
\hline SR & Social status & $\mathrm{K}$ & $\%$ \\
\hline 1 & Single & 27 & $60 \%$ \\
\hline 2 & Married & 18 & $30 \%$ \\
\hline & Total & 45 & 100 \\
\hline SR & Age & $\mathrm{K}$ & $\%$ \\
\hline 1 & $25-30$ & 33 & 73.3 \\
\hline 2 & $35-40$ & 12 & 27.7 \\
\hline Total & & 45 & $100 \%$ \\
\hline
\end{tabular}


The above table shows that most of the social workers working in the hospital are men, most are unmarried, and most of them are between the ages of 25-30.

First hypothesis: There is a statistically significant direct relationship between the professional performance of the general practitioner in social work and the improvement of health services for patients.

Table (10) shows the relationship between the average scores for professional performance and health services

\begin{tabular}{|l|l|l|l|}
\hline Dimensions & Mean & S. D & The Value of t \\
\hline Professional performance & 2.5 & 0.69 & $0.757-$ \\
\hline health services & 2.68 & 0.61 & \\
\hline
\end{tabular}

The above table shows a statistically significant indication between the average scores for the professional performance scale and the health care services. This confirms the first research hypothesis. The previous table shows the relationship between the professional performance of the general practitioner in the social work and the improvement of health services. It increases daily through monitoring diseases that need various health initiatives that are provided free of charge to all families and ages. It provides health services to the groups of society as a whole because of their high costs, which the general practitioner in the social service through writing reports and carrying out the procedures in which he participates with the medical staff.

Second hypothesis: There is a direct relationship of statistical significance between the professional performance of the general practitioner in social work and the improvement of economic services.

Table (11) shows the relationship between the average scores for professional performance and economic services

\begin{tabular}{|l|l|l|l|}
\hline Dimensions & Mean & S. D & The Value of t \\
\hline Professional performance & 2.5 & 0.69 & $0.959-$ \\
\hline Economic services & 2.72 & 0.56 & \\
\hline
\end{tabular}

The above table shows a statistically significant indication between the average scores for the professional performance scale and the economic services. This confirms the second research hypothesis. In addition, table shows the relationship between professional performance and the improvement of economic services which leads to the importance of the role of the general practitioner in the social work in providing a helping hand and support through the provision of economic assistance provided by the Ministry of Health for the care of patients. This is what we find in Mr. President's initiative to take care of the health aspect of citizens, as well as provide adequate 


\begin{tabular}{||cr|}
\hline \multicolumn{2}{|c|}{ The Egyptian Journal of Social Work (EJSW) https://ejsw.journals.ekb.eg/e } \\
ISSN: $2356-9204$ & Vol 11, Issue.1, January2021 \\
\hline
\end{tabular}

information on institutions that provide economic services for medical care, whether governmental or civil.

Third hypothesis: There is a statistically significant direct relationship between the professional performance of the general practitioner in social work and the improvement of social services.

Table (12) shows the relationship between the average scores for professional performance and Health Care Services. $\quad \mathrm{N}=45$

\begin{tabular}{|l|l|l|l|l|}
\hline Dimensions & Mean & S. D & The Value of t & Level of significance \\
\hline $\begin{array}{l}\text { Professional } \\
\text { performance }\end{array}$ & 2.5 & 0.69 & $0.663-$ & Significant \\
\cline { 1 - 3 } Social services & 2.66 & 0.63 & & \\
\hline
\end{tabular}

The above table shows a statistically significant indication between the average scores for the professional performance scale and the social services. This confirms the third research hypothesis.

The previous table shows the relationship between professional performance and the improvement of social services which results from the methods used to educate families about diseases and how to prevent them. It also shows the speed of participation in various medical initiatives provided by Mr. President's initiative to provide social services to families through the fruitful role played by the general practitioner.

The study hypotheses were also verified on finding a positive, statistically significant relationship of the professional performance of the general practitioner

1. There is a positive statistically significant relationship between the professional performance of the general practitioner in social work and the improvement of health care services for patients.

2. There is a positive statistical significance between the professional performance of the general practitioner in social work and the improvement of economic services.

3. There is a positive statistically significant direct relationship between the professional performance of the general practitioner in social work and the improvement of social services.

\section{References}

Abbas, Mohammed, S. and Ali, Hussein (1999). Human Resources

Management, Dar Wael, Amman, Jordan, Edition 1.

Abdel - Moaty et al. (2012). Family Sociology, Alexandria, University, Knowledge House.

Al-Nuuhi, F. Abdelaziz (2002). General practice in social work is the process of solving the problem within the framework of ecological, Helwan University, Faculty of Social work.

Abdul Muhi, Saleh (2013). Social work and medical practice, Alexandria, University Knowledge House. 


\begin{tabular}{||cr||}
\hline The Egyptian Journal of Social Work (EJSW) https://ejsw.journals.ekb.eg/e \\
ISSN: $2356-9204$ & Vol 11, Issue.1, January2021 \\
\hline \hline
\end{tabular}

Abu Al-Maati, A. Maher (2012). General practice of social service in the medical field and care for the handicapped, Faculty of Social Work Helwan University.

Abu Al-Maati, Maher (2011). A Guide to Field Visits in the Fields of Social Work, Cairo, Zahraa Al-Sharq Library.

Allam, M. Etimad (2009). Egyptian youth and new occupations opportunities and connotations - in Egyptian youth issues present challenges and future prospects.

Al-Saqour, Saleh (2010). Encyclopedia of Contemporary Social Work, "Glossary of Terms", Amman, Zahran Publishing.

House. Ammar, Ali Al-Hadi (2002). The relationship of job stress with contentment and job performance, unpublished Master Thesis, Academy of Graduate Studies, Department of Administration and Organization, Tripoli, Libya.

Bob, Harvard (2001). Translation of the Division of Economics and Management Sciences, Cairo, Al-Faruq Publishing and Distribution.

Briland, Donald (2003). History and evaluation of Social Work Practice Encyclopedia of Social Work. Maryland, N.A.S.W, press.

Cambridge Dictionary of American English (2000). Cambridge University press.

Chui, W.H Wilson (2006). Social Work and Human Series best Practice, Australia, Federation press.

Charles, Garven: (2017). Social Work and Direct Practice, London, Sage publication.

Derezates S. David. (2005). Advanced Generalist social work Practice, California, Sage Publication.

Douglas K (2004). Managing Change of Individuals and Performance-How? Translated by Abdul Hakim Ahmed. Al-Khazmi, Cairo, Itrak Printing and Publishing.

El-Nouhy, F. Abdelaziz (2002). General Practice in Social Work, Cairo, without publishing authority.

Gary, W. \& Bradford, P. (2016). Intervention Strategies and Research with Socially Isolated Children "An Ecological-systems perspective's, Small Group Research, V.14, N0.2.

Gharaibeh, Mahmoud Faisal (2008). Social Medical Service, Amman, Dar Wael.

Gregory, Pawlson (2019). "Health Care Systems", Geneva Switzerland

Hasan, Abdel-Basit (1997) Social Development, Cairo, Wahba Library.

Hasan, Fuqua (2006). Health Disability, Cairo, Modern Book House.

Hashem, M. Hashem (2005). Professional Development Requirements

For Social Workers Working in Community Development Societies, research published in the Sixteenth Conference, Faculty of Social Work, Cairo University, Fayoum.

Abdel Majid S. Hesham, (2005). General Practice of Social worker,

A Contemporary Vision of the Education and Practice of Social work in the Arab World, $18{ }^{\mathrm{sc}}$ ientific Conference, Helwan University, Faculty of Social work.

Bashir, Iqbal et al. (1987). Professional practice of social work in the medical and Rehabilitation, Alexandria: modern university office. Al-Ghazzawi, Jalaluddin, (2004). Practice Skills in Social Work, Alexandria, Art Radiation Library.

Habib J. Shehata (1997). The relationship between the application of a training program for social workers and the development of their professional performance in the Field of social defense, journal of studies in social work and humanities, Faculty of Social worker, Helwan University, second issue, 1997. 
Jon L. Pierce et al. (2002). Management and organization Behavior, South Western, Australia.

Lindsay, Hill (2009). Inter-professional Learning to Prepare Medical and Social Work Students for Practice with Refugee and Asylum Seekers, Social Work Education, vol. 28 issue, 3.

Abu Al-Maati. Maher (2014). Modern Trends in General Practice in

Social work, Alexandria, Modern University Office.

Mahmoud, A. Safaa (2013). Professional creativity requirements for social workers in the medical field, Helwan University, Faculty of Social Work, Twenty-six ${ }^{\text {th }}$ Scientific Conference, Vol.14.

Michele, Peters, el. (2013). Career quality of life and experiences of health services: A Cross- sectional survey across three neurological conditions (Health \& Quality of Life Outcomes, Vol. 11, issue 1, 2013.

Mohammed, Al Badawi and Safi, Khalifa (2011). "Professional Skills of a Social Worker", Alexandria, Modern University Office.

Mokhtar, Ajjouba (1990). Social welfare and its impact contemporary social work Portals, Riyadh, Dar al- Bloom printing and Publishing.

Nasr K. Omran (1999). The Challenges of Social work Practice in Medical Institutions and Planning to Address Them, Published Research, Journal of Studies in Social Work and Humanities, College of Social work, Helwan University.

Palmela, London S. (2002). "Generalist -c\& advanced generalist practice in Richard". L. Edwards's editor, in chief. Encyclopedia of social work Washington, NAS press, $19^{\text {th }}$, Vol. (2).

Pickett, Rosalle (2006). Learning from each other: The social work role as an integrated part of hospital disaster response. Haworth press. Vol. 43.

Slack (2007). Training Needs Assessment Procedures. Retrieved from (www.group.slac.standorf.edu)

World Health Organization. (2019). Anniversary of small pox eradication, Geneva, 18 June, 2019.

(www.encyclopedia.com,Retrieved24-03-2019)

Zymula, G. et al. (1999). Reappraisal of Vocational Evaluation from

An Ecological System Perspective, Journal of Rehabilitation

Literature, V.47, N.10. 